\title{
Two decades of Earth system modeling with an emphasis on Model for Interdisciplinary Research on Climate (MIROC)
}

\author{
Michio Kawamiya ${ }^{1 *}$ D, Tomohiro Hajima ${ }^{1}$, Kaoru Tachiiri ${ }^{1}$, Shingo Watanabe ${ }^{1}$ and Tokuta Yokohata ${ }^{2}$
}

\begin{abstract}
The past 20 years of research using Earth system models (ESMs) is reviewed with an emphasis on results from the ESM based on MIROC (Model for Interdisciplinary Research on Climate) developed in Japan. Earth system models are climate models incorporating biogeochemical processes such as the carbon cycle. The development of ESM was triggered by studies of the feedback between climate change and the carbon cycle. State-of-the-art ESMs are much more realistic than the first ESMs. They now include various biogeochemical processes other than carbon, such as atmospheric chemistry and the nitrogen and iron cycles as well as nutrient transport by atmospheric dust and rivers. They are used to address many practical issues, such as evaluating the amount of carbon dioxide emissions that is consistent with climate change mitigation targets, and are indispensable tools for the development of climate change mitigation policies. Novel, ambitious attempts to use ESMs include coupling socioeconomics with Earth systems, and projecting the carbon cycle on decadal timescales. Development of ESMs requires ongoing integration of multiple aspects of climate science. Emerging applications of ESMs can bring forth meaningful insights, and should be directed toward expanding connections with fields outside climate science, e.g., socioeconomics.
\end{abstract}

Keywords: Earth system model, Climate change, IPCC, Carbon cycle, Biogeochemistry, Interdisciplinary project, Remaining carbon budget, Socioeconomics, Nitrogen, Iron

\section{Introduction}

\subsection{Manifestations of climate change}

The effects of climate change are now noticeable. For example, the World Meteorological Organization (WMO) pointed out that climate change is one of the factors underlying the floods and disastrous heatwave in Japan in 2018 (WMO 2018). The general public is also starting to identify manifestations of climate change. To meet the demands of society, it is increasingly important to avoid the dangerous consequences of climate change

\footnotetext{
* Correspondence: kawamiya@jamstec.go.jp

'Japan Agency for Marine-Earth Science and Technology, 3173-25,

Showamachi, Kanazawa-ku, Yokohama, Kanagawa 236-0001, Japan Full list of author information is available at the end of the article
}

on the basis of scientific knowledge. Climate models can contribute by, for example, providing estimates of changes in frequency of extreme events under climate change (cf., Imada et al. 2019).

Up until the early 2000s, the priority for many climate scientists was to focus on improving our scientific understanding of climate change, such as detection of human impacts and validation of climate models for projection. In 2007, the $4^{\text {th }}$ Assessment Report (AR4) of the Intergovernmental Panel on Climate Change (IPCC) reported dominant human influence on the warming of the atmosphere and the ocean since the mid-twentieth century (IPCC 2007). This was perhaps the turning point; it put an end to the question of whether climate 
change was real, and encouraged scientists to direct more efforts toward obtaining reliable data that could be used for planning mitigation and adaptation processes, rather than proving human influence on climate.

\subsection{Contribution of climate models to the design of climate change mitigation and adaptation strategies} Detailed information on climate change tailored to individual regions is needed to support regional planning efforts. For example, high-resolution climate models are being used to establish regional adaptation strategies (JMA 2017), not only in Japan, but also worldwide. The Working Group I contribution to IPCC's $6^{\text {th }}$ Assessment Report (AR6) will be published in 2021. Three of the twelve chapters are devoted to regional-scale projections, and will discuss regional effects linked to global scale changes, extreme events (such as tropical cyclones), and the impacts of hazards (IPCC 2017).

Projections of climate change can underpin measures against climate change, and Earth system models (ESMs), in which biogeochemical processes such as the carbon cycle are coupled with the physical climate system, are often used to design climate change mitigation strategies to reduce anthropogenic greenhouse gas emissions. While conventional climate models require carbon dioxide $\left(\mathrm{CO}_{2}\right)$ concentration data as inputs, ESMs can directly use anthropogenic $\mathrm{CO}_{2}$ emissions as inputs, and are therefore able to express more explicitly the link between environmental change and climate change mitigation policies.

In this review, we focus on possible contributions of ESMs to the design of climate change mitigation policies, accentuating results obtained using the Model for Interdisciplinary Research on Climate (MIROC)-based ESM, which is currently being developed in Japan. Earth system models can be classified into three categories according to their degree of complexity (Hajima et al. 2014a): conceptual models, ESMs with intermediate complexity (EMICs), and ESMs based on general circulation models (GCMs). This review incorporates developments that have been published since the review of Hajima et al. (2014a). In the present review, unless otherwise specified, the term $\operatorname{ESM}(\mathrm{s})$ refers to the third category, i.e., $\operatorname{ESM}(\mathrm{s})$ based on $\operatorname{GCM}(\mathrm{s})$, which are the models that are used most frequently to understand potential consequences of greenhouse gas emission scenarios. Claussen et al. (2002) provides an excellent review of EMICs, which can also be used for climate change projections, especially over longer timescales, such as millennia.

Feedback resulting from interactions between climate change and the carbon cycle is a dominant motivation behind ongoing development of ESMs. Therefore, this present review provides an overview that starts with this feedback, and then continues to cover other aspects while highlighting the MIROC-based ESM. Nevertheless, the overall direction of ESM research clearly involves the interests of the international community.

\section{Review}

2.1 The dawn of Earth system models: climate-carbon cycle feedback

One of the reasons ESMs first attracted attention is that feedback from the carbon cycle was shown to have the potential to accelerate climate change (Cox et al. 2000; Friedlingstein et al. 2001). Since then, several institutes have developed their own ESMs by introducing many component models into their GCMs; these include the dynamic global vegetation model (DGVM), which projects changes in vegetation cover of natural land system, and the carbon cycle model with fixed vegetation types, which focuses on forecasting carbon exchange (e.g., Friedlingstein et al. 2006, and references therein). These terrestrial component models affect climate via the biogeochemical (carbon cycle) processes but also through the impact of biophysical processes such as changes in leaf area index on surface albedo (e.g., Abe et al. 2017).

In Japan, the Meteorological Research Institute (MRI) has been developing an ESM based on its GCM (Yukimoto et al. 2011). The Japan Agency for Marine-Earth Science and Technology (JAMSTEC), in collaboration with the National Institute of Environmental Studies, Atmosphere Ocean Research Institute of the University of Tokyo, and a community of other universities (Team MIROC) has been developing another GCM-based ESM (Hajima et al. 2020; Kawamiya et al. 2005; Watanabe et al. 2011a). Figure 1 depicts the structure of the ESM that Team MIROC first developed. This ESM consists of:

- The atmosphere-ocean coupled climate model MIROC (Hasumi and Emori 2004; Tatebe et al. 2019; Watanabe et al. 2010)

- The terrestrial ecosystem model Sim-CYCLE (Ito and Oikawa 2002)

- The simple NPZD-type ocean ecosystem model, which includes dissolved inorganic nitrogen $(\mathrm{N})$, phytoplankton $(\mathrm{P})$, zooplankton $(\mathrm{Z})$, and detritus $(\mathrm{D}$; Oschlies and Garçon 1999)

- The land surface model MATSIRO (Takata et al. 2003), and

- The aerosol transport model SPRINTARS (Takemura et al. 2000)

A full atmospheric chemistry component model, known as CHASER (Sudo et al. 2002), was integrated into the ESM at a subsequent stage (Watanabe et al. 


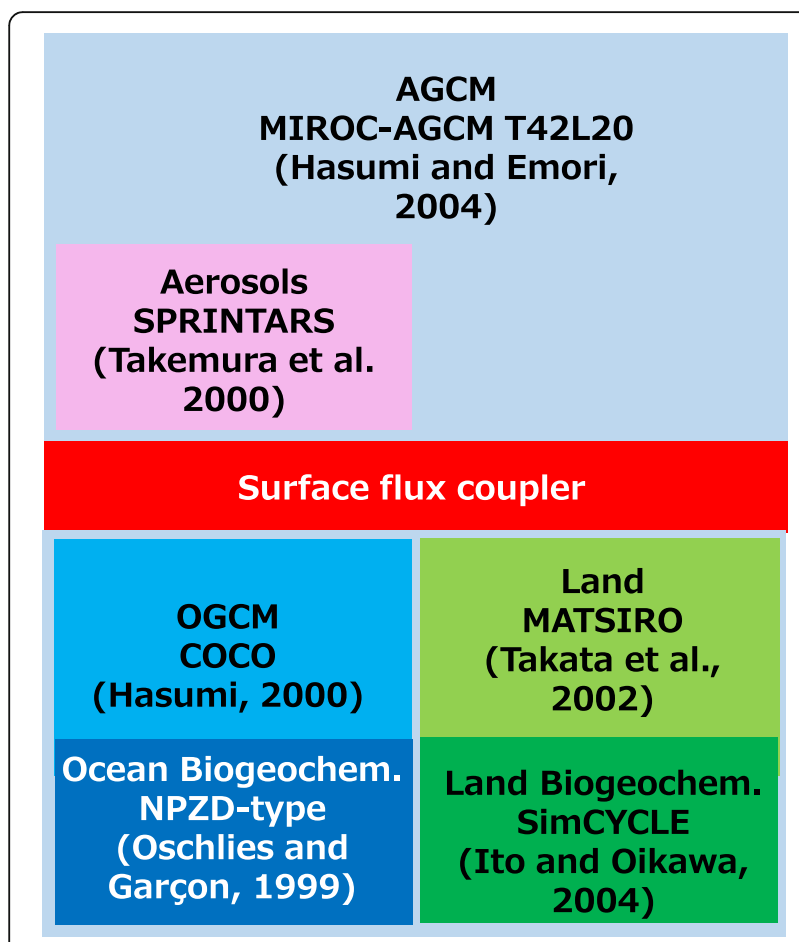

Fig. 1 Structure of the original version of the Earth system model (ESM) used for the Coupled Model Intercomparison Project (CMIP) Phase 3, developed by Team MIROC. From CMIP Phase 5 onwards, the full atmospheric chemistry component model CHASER was added. The land biogeochemical model was later replaced by SEIBDGVM for CMIP Phase 5 and then by VISIT for CMIP Phase 6. All model acronyms are listed in the Abbreviations

2011a) (see Fig. 3). All model acronyms are spelled out in full in the Abbreviations section. Component models have been developed separately in different scientific fields. In ESMs, they are often updated, and sometimes replaced with other component models that may be more appropriate for specific purposes (Hasumi 2000; Inatomi et al. 2010; Sato et al. 2007). The fundamental structure of Team MIROC's ESM, as outlined in Fig. 1, is common to that of other ESMs being developed at other institutes.

The Coupled Climate-Carbon Cycle Model Intercomparison Project ( $C^{4} \mathrm{MIP}$ ) was initiated in the early 2000s to explore issues related to climate-carbon cycle feedback in participating models (Friedlingstein et al. 2006). Climate-carbon cycle feedback has a mainly positive (accelerating) effect on climate change because higher temperature enhances decomposition of soil organic matter and plant respiration, and inhibits photosynthesis. Because of thermodynamic effects on air-sea gas exchange, higher temperature also suppresses ocean carbon uptake, but global impact of this marine process is minor compared with that of terrestrial processes.

Feedback intensity-defined as the difference between $\mathrm{CO}_{2}$ concentrations at year 2100 with climate-carbon cycle interactions and $\mathrm{CO}_{2}$ concentrations at year 2100 without these interactions-is highly dependent on models. They range from 20 to $224 \mathrm{ppm}$ (Friedlingstein et al. 2006), which correspond to temperature differences of $\sim 0.2{ }^{\circ} \mathrm{C}$ to $>2{ }^{\circ} \mathrm{C}$. It is difficult to obtain precise temperature conversions though, because of the many factors that are model specific. Various factors are involved in determining the feedback intensity, including equilibrium climate sensitivity, transient climate response of the base climate model, and properties of the embedded carbon cycle model. Thompson et al. (2004) pointed out that models with strong $\mathrm{CO}_{2}$ fertilization tend to have moderate to weak feedback, because carbon added to the atmosphere will be immediately absorbed by terrestrial vegetation. Although $\mathrm{CO}_{2}$ fertilization itself is considered as a negative feedback on climate change, it is not explicitly linked to temperature rise. Instead, elevated $\mathrm{CO}_{2}$ concentrations lead to more vigorous $\mathrm{CO}_{2}$ uptake, counteracting climate change. Hajima et al. (2014b) later showed that the range in this model feedback intensity is a result of the choice of formulation and parameter values for modeled photosynthesis.

The Coupled Model Intercomparison Project (CMIP) has an ongoing critical role in contributing to IPCC reports. As a result of $\mathrm{C}^{4} \mathrm{MIP}$ contributions to the IPCC's $5^{\text {th }}$ Assessment Report (AR5), the scientific community became aware of the importance of incorporating the carbon cycle into climate change projections, and incorporated experiments using ESMs with carbon cycle in the protocols of the $5^{\text {th }}$ (CMIP5) and subsequent phases of CMIP (Hibbard et al. 2007; Taylor et al. 2011). Concentration-driven experiments were formally adopted for $\mathrm{C}^{4} \mathrm{MIP}$ under CMIP5; $\mathrm{CO}_{2}$ concentrations, not emissions, were used as input data for integrating ESMs, and carbon cycle components were activated; on the basis of global carbon balance, ESM output was used to determine anthropogenic $\mathrm{CO}_{2}$ emission, which was then used to evaluate climate change impact on the carbon cycle.

Because the causal relationship in reality starts from $\mathrm{CO}_{2}$ emission rather than concentration, the CMIP protocol is rather counterintuitive for experiments involving the carbon cycle. However, by making concentration-driven experiments accessible to models without carbon cycle, it allows more models to participate in CMIP. It also allows for direct comparison between ESM outputs and socioeconomic emission scenarios, as explored in the Representative Concentration Pathways (RCPs; Moss et al. 2010) from Integrated Assessment Models (IAMs). On average, there is a good match between ESM outputs and IAM projections. Under the highest emission scenario of RCP8.5, however, mean ESM-based emission is $85 \%$ that of mean IAM-based emission (Jones et al. 2013), implying that 
terrestrial and oceanic carbon sinks in ESMs are smaller than those in IAMs. This may reflect insufficient expression of the carbon cycle feedback in IAMs, or differences between ESMs and IAMs in terms of the implementation of land use and land cover change. Jones et al. (2013) highlighted that the IAM used for developing RCP8.5 was calibrated using an ESM with a relatively large oceanic sink.

While there is a good match between average values from ESMs and IAMs, ESM output scatter is large because of uncertainties in the global carbon cycle, making it impossible to identify specific emission levels even when different ESMs target the same $\mathrm{CO}_{2}$ concentration scenario. Matsumoto et al. (2016) evaluated impacts of Earth system uncertainties, including those of the carbon cycle on socioeconomics, especially mitigation policy; under RCP4.5, inefficient carbon uptake and/or high climate sensitivity would result in stringent emission cuts and future carbon prices that are roughly $300 \%$ of those under efficient carbon uptake and/or low climate sensitivity. Since the disciplines of natural sciences and socioeconomics on climate change are related, there should be a room for expanding collaborations between researchers from these different disciplines. The study of Matsumoto et al. (2016) is one of the successful initiatives, in which ESM development facilitated collaboration between researchers from climate science and socioeconomics, enabling the conversion of uncertainties in natural processes into those related to socioeconomics. Sokolov et al. (2005), Yang et al. (2016), and Mercure et al. (2018) also developed platforms linking ESMs (including EMICs) with socioeconomic models, catalyzing interactions between different disciplines that are related.

\subsection{Sophistication of Earth system models 2.2.1 Incorporating the nitrogen cycle}

While most ESM studies report a positive climate-carbon cycle feedback that accelerates climate change, Thornton et al. (2007) showed that feedback became negative when the nitrogen cycle was incorporated into their model. They reported that higher temperatures enhance remineralization of soil organic nitrogen, which in turn supplies more nutrients, and stimulates photosynthesis of terrestrial vegetation. Two of the nine models in CMIP5 included the nitrogen cycle. Both of them were based on the community land model (CLM4) of Lawrence et al. (2011), and the climate-carbon cycle feedback was considerably weaker in these models relative to that in the other CMIP5 models (Arora et al. 2013). While net primary production should be strongly regulated by heterotrophic respiration according to Thornton et al. (2007), decomposition of carbon-concentration feedbacks into land ecophysiological and soil processes showed no conclusive supporting evidence (Hajima et al. 2014b). Nevertheless, models with the nitrogen cycle behave in a distinct manner, as demonstrated by the results of CESM1-BGC and NorESM1$\mathrm{ME}$, which are both models with the nitrogen cycle and outliers in CMIP5 (Fig. 2 with data from Hajima et al. 2014b). Zaehle et al. (2014) suggested that CMIP5 models without the nitrogen cycle possibly overestimate uptake of anthropogenic carbon, and Wieder et al. (2015) highlighted effects of interactions between the phosphorus and carbon cycles.

These studies clearly support the incorporation of interactions between the cycles of carbon and other elements, especially nitrogen, into ESMs. Several of the ESMs joining CMIP6 (Eyring et al. 2016; Jones et al. 2016; Lawrence et al. 2016; Orr et al. 2017) are performing experiments that require the incorporation of the nitrogen cycle. This includes MIROC-ES2L, which is the first version of the MIROC-based ESM to include the terrestrial nitrogen cycle. Figure 2 shows CMIP6 values from Arora et al. (2020). As indicated by Arora et al. (2020), CMIP6 models with explicit nitrogen cycle (filled blue squares in Fig. 2) show moderate response of net primary productivity (NPP) to $\mathrm{CO}_{2}$ increase and the resultant increase of land total carbon; the smallest response was given by the model that has incorporated the phosphorous cycle and limitation on plant growth (ACCESS-ESM1.5). Carbon cycle behavior in MIROCES2L-the latest version of MIROC-is similar to that in MIROC-ESM - the former version of MIROC used for CMIP5. This can be seen in Fig. 2, where MIROC-ES2L lies far from the origin, and is, in fact, further away from the origin than MIROC-ESM. This may be at least partly because, in MIROC-ESM, parameter values were set to produce a modest $\mathrm{CO}_{2}$ fertilization effect, implicitly taking soil nitrogen limitation into consideration. Like MIROC-ESM, $\mathrm{CO}_{2}$ fertilization effect in MIROC-ES2L is moderate (see Fig. 2). Therefore, relative to MIROCESM, the enhanced sensitivity of NPP and terrestrial carbon of MIROC-ES2L is likely attributable to the longer soil carbon residence time and higher carbon use efficiency in MIROC-ES2L (Arora et al. 2020). Wenzel et al. (2016) examined the validity of the $\mathrm{CO}_{2}$ fertilization effect that emerged in CMIP5 models; they compared model outputs with observations and found that MIROC-ESM responds realistically to $\mathrm{CO}_{2}$ increase. Incorporation of the nitrogen cycle into the terrestrial component model of the ESM enables evaluation of impacts of human activities, such as addition of nitrogen to ecosystems through agricultural fertilization. Bonan and Doney (2018) indeed pointed out that taking agriculture into consideration with nitrogen dynamics is a key for utilizing ESMs to establish mitigation policy. ESMs are becoming a tool to assess the impacts of various human 


\section{Terrestrial response to $\mathrm{CO}_{2}$ increase}

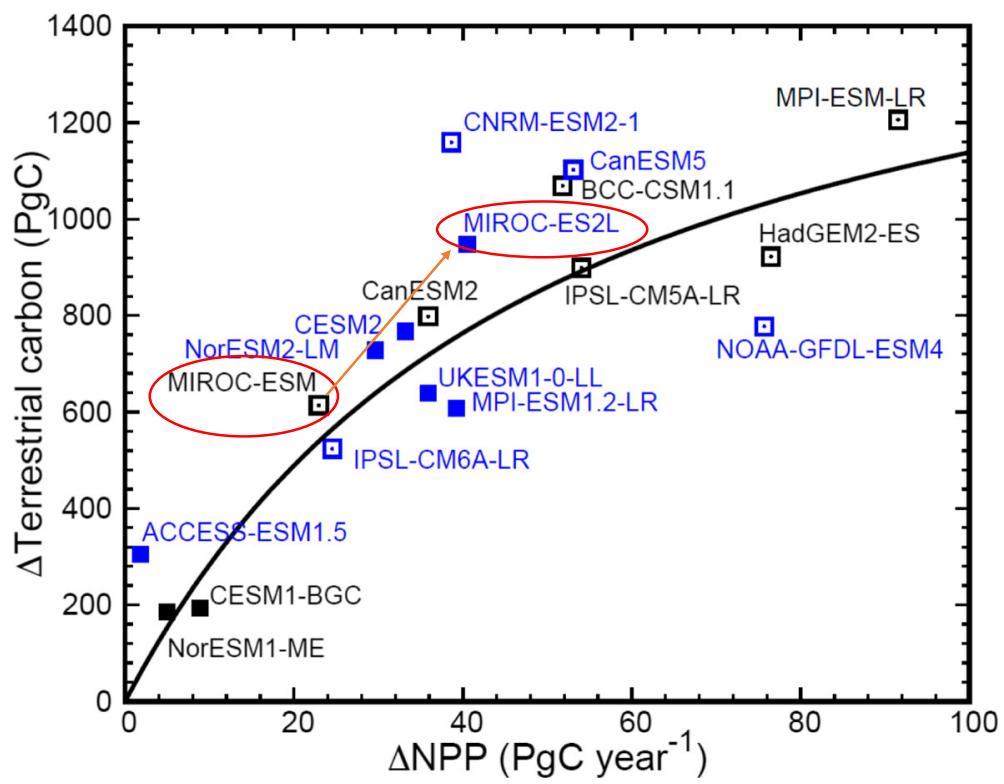

Fig. 2 Relationship between net primary production increments $(\triangle N P P)$ and terrestrial carbon accumulation stimulated by atmospheric $\mathrm{CO}_{2}$ increase in Coupled Model Intercomparison Project (CMIP) Phase 5 (black) and 6 (blue) models based on results from an idealized CMIP5 (Hajima et al. 2014a, 2014b) and CMIP6 (Arora et al. 2020) experiment in which $\mathrm{CO}_{2}$ concentration was increased every year by $1 \%$ and the carbon cycle was assumed to be unaffected by temperature change. Increments were calculated as the difference between the last and first conditions of the experiments. Filled symbols indicate results from models with terrestrial carbon-nitrogen interactions. Solid curve indicates results from the analytical, simple algebraic model based on parameters of CMIP5 models, as proposed by Hajima et al. (2014b). Red ovals indicate results from MIROC series of ESMs

activities, in addition to $\mathrm{CO}_{2}$ emission, on global systems.

\subsubsection{Connecting land and ocean via nitrogen}

River transport is incorporated into MIROC-ES2L; a certain portion of active nitrogen on land is carried by rivers into the ocean; this terrestrial component becomes part of the marine inorganic nitrogen, which is consumed in oceanic phytoplankton photosynthesis (Hajima et al. 2020). For CMIP5, MIROC-ESM only had a closed nitrogen cycle in the ocean. For CMIP6, nitrogen cycles on land and ocean are linked in MIROC-ES2L; the modeled ocean has an additional source of nitrogen, necessitating explicit treatment of nitrogen sinks and other sources within the ocean. Like many other ESMs in CMIP6, MIROC-ES2L takes nitrogen fixation and denitrification into consideration. Dust deposition of nitrogen from the atmosphere is externally provided as input data. The impacts on oceanic net primary production of river transport and atmospheric deposition have been examined by Hajima et al. (2020). The effect of anthropogenic nitrogen river loading is becoming detectable in some coastal regions, albeit not at basin or larger scales (Gruber and Galloway 2008; Rabalais 2002). However, it would be desirable for future model development to include physical transport processes near coasts, thereby enabling evaluation of impacts of nitrogen loading, which can undergo explosive increases related to population growth (Bodirsky et al. 2012).

\subsubsection{Introducing the iron cycle into the ocean}

Along with nitrogen fixation and denitrification, iron cycling is another process that is often neglected in ESMs, despite its importance. Martin and Fitzwater (1988) first presented convincing data to illustrate the indispensable role of iron as a nutrient. Research on iron cycling has shown that $\mathrm{CO}_{2}$ concentration variation over glacial-interglacial cycles was at least partly triggered by iron transported as dust, which oscillated in synchronization with the climate cycle (Ohgaito et al. 2018). It was thought that perhaps climate warming could be somewhat mediated by distributing iron over the ocean (so-called geoengineering; Boyd 2008). Although subsequent field experiments have indicated that iron fertilization is not an efficient way of slowing down climate change (Williamson et al. 2012), the effect of iron on $\mathrm{CO}_{2}$ fluctuation over geological time scales of $100 \mathrm{ka}$ is now widely accepted (Yamamoto et al. 2019). There is also firm recognition that iron is the key limiting factor for phytoplankton growth in oceanic regions 
having high nutrient and low chlorophyll levels, such as the Southern Ocean, Equatorial Pacific, and Northernmost Pacific regions (Sarmiento and Gruber 2006).

Iron supply via atmospheric dust is a vital part of the oceanic iron cycle. Influxes of iron to the ocean have conventionally been evaluated by multiplying dust deposition (e.g., Duce and Tindale 1991; Jickells et al. 2005) by a constant parameter (Duce et al. 1991). This simple approach was adopted because of a lack of adequate observation data, although clearly this is insufficient to reproduce the geographical distribution of iron inputs. Currently, process-based models are being developed that may be able to capture the geographical distribution. One example is the model by Ito et al. (2019), which takes into account the key process associated with pyrogenic iron changes. In MIROC-ES2L, pyrogenic and lithogenic iron are differentiated, although emission of pyrogenic iron is prescribed as input data. Treating pyrogenic and lithogenic iron separately is a characteristic feature of the MIROC series of ESMs, and enables special variation in solubility of iron supplied to the ocean to be reproduced (Hajima et al. 2020).

Besides nitrogen and iron cycling, another important biogeochemical process yet to be incorporated into many (including the MIROC series) of the existing ESMs is $\mathrm{CO}_{2}$ or $\mathrm{CH}_{4}$ emissions related to permafrost thawing, as pointed out by the IPCC (2018). Despite this issue being known for many years, model development has been hampered by the scarcity of data. Some modeling groups have started to embed detailed treatment of permafrost, as observation data become available (Xia et al. 2017).

\subsubsection{Incorporation of short-lived climate forcers}

As low-emission scenarios to limit global warming to 2 ${ }^{\circ} \mathrm{C}$ or $1.5^{\circ} \mathrm{C}$ below preindustrial levels are emphasized in discussions of climate change mitigation measures, attention is focused on the treatment of climate driving forcers other than $\mathrm{CO}_{2}$. The Special Report on Global warming of $1.5^{\circ} \mathrm{C}$ (SR1.5) by the IPCC (2018) estimated the total future $\mathrm{CO}_{2}$ emissions consistent with the $1.5^{\circ} \mathrm{C}$ target (this quantity is often referred to as the remaining carbon budget and will be discussed later in more detail). Contributions from non- $\mathrm{CO}_{2}$ forcings and response of the earth system to them are considered as the largest sources of uncertainty underlying remaining carbon budget estimates.

These forcing agents are termed as short-lived climate forcers (SLCFs) since they tend to have shorter residence times than $\mathrm{CO}_{2}$ because of their high chemical reactivity in or rapid deposition out of the atmosphere. At its $49^{\text {th }}$ plenary in 2019, the IPCC decided to revise SLCF inventory methodology to improve the emissions dataset (IPCC 2019). This development can serve as a timely stimulus for the development of ESMs that explicitly incorporate full atmospheric chemistry.

The MIROC-ESM-CHEM (Watanabe et al. 2011a) was the first version of Team MIROC's ESM (Fig. 3a) with a full atmospheric chemistry component (Sudo et al. 2002). It participated in CMIP5, and was also used to project future changes in UV-B reaching the Earth's surface (Watanabe et al. 2011b; Watanabe and Yokohata 2012) because of its detailed treatment of stratospheric chemistry and a top of the atmosphere that extends to a height of $85 \mathrm{~km}$. However, incorporation of full atmospheric chemistry requires following the reactions and transport of more than fifty three-dimensional tracers, which is computationally demanding. While MIROC-ESM-CHEM simulations were at the coarse horizontal resolution of T42 (280 $\mathrm{km})$, they only covered a small portion of CMIP5 experiments.

The MIROC-ES2H is the latest version of the MIROC series for CMIP6 with full chemistry (Sudo et al. 2002). Except for the treatment of atmospheric chemistry and horizontal resolution, it has inherited most of the features of MIROC-ES2L. It is at T85 $(140 \mathrm{~km})$ resolution, which is relatively high for such a complex model. Because computational load would be unrealistically high if the chemical component were to be directly coupled with the main body of the ESM, the atmosphere-only model with full chemistry is run at T42 in parallel with the main coupled model at T85 (Fig. 3b). The model coupling software Jcup (Arakawa et al. 2020) exchanges data between the T42 and T85 models, and computational requirements are maintained at a level that can be feasibly met.

The MIROC-ES2H has been used to develop SLCF reduction scenarios (Nakajima et al. 2020), and covers parts of CMIP6 experiments. Comparison between Figs. 1 and 3a, b illustrates how an ESM becomes elaborate over time and needs increasingly advanced programming techniques. Chemical processes in the atmosphere can have impacts on the biosphere through, for instance, deposition of nitrate and ammonium on land and ocean. While depositions are provided as external inputs in MIROC-ES2L, they are computed in MIROC-ES2H. On land, this nitrogen accumulation eventually leads to release of $\mathrm{N}_{2} \mathrm{O}, \mathrm{N}_{2}$, and $\mathrm{NH}_{3}$ out of the land cycle (Gruber and Galloway 2008), which is implemented in MIROCES2H (and MIROC-ES2L) only diagnostically without feedbacks to atmospheric chemistry (Hajima et al. 2020). Introducing more sophisticated interactions between atmospheric chemistry, biosphere, and the carbon cycle would be the next step in ESM development beyond CMIP6. 


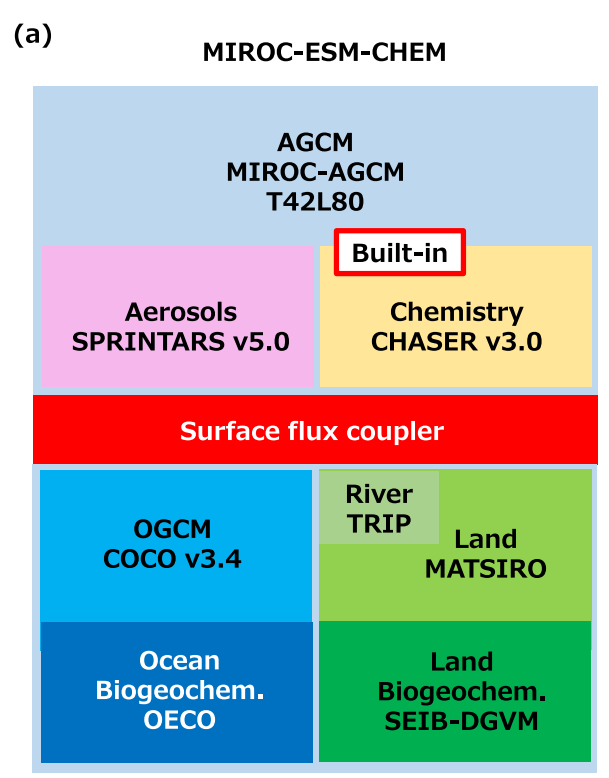

(b)

MIROC-ES2H

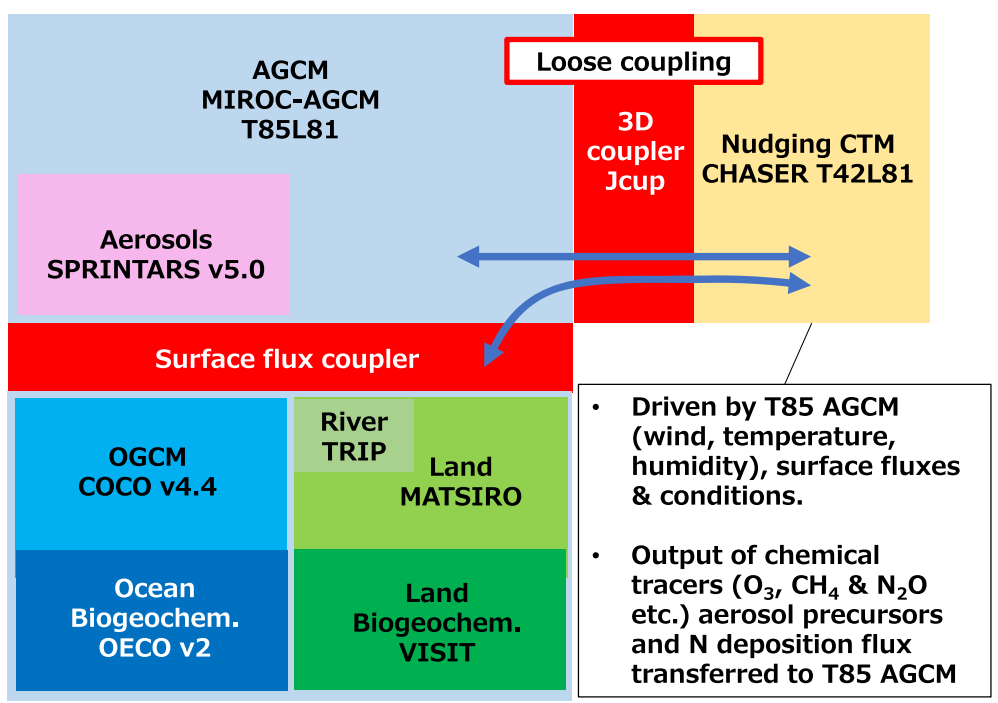

Fig. 3 Coupling of component models in a MIROC-ESM-CHEM used for CMIP5 and b MIROC-ES2H used for CMIP. T42 and T85 indicate horizontal resolutions that correspond to approximately 280 and $140 \mathrm{~km}$, respectively. L80 and L81 indicate 80 and 81 vertical layers in the atmospheric model.

\subsection{Expanding areas of application}

\subsubsection{Contributions to decision making}

The Paris Agreement-the framework of measures from 2021 to 2030 to reduce climate change-entered into force in 2016. It aims to hold global temperature increase to below $2{ }^{\circ} \mathrm{C}$ above preindustrial levels, and pursue efforts to limit warming to below $1.5{ }^{\circ} \mathrm{C}$ (UNFCCC 2015). While the $2{ }^{\circ} \mathrm{C}$ target was often mentioned in international negotiations prior to the Paris Agreement, the $1.5{ }^{\circ} \mathrm{C}$ target was relatively new and hence studies of the impacts of $1.5{ }^{\circ} \mathrm{C}$ warming were relatively scarce. Therefore, since the signing of the Paris Agreement, numerous studies have been conducted to investigate the differences between impacts of a $1.5{ }^{\circ} \mathrm{C}$ warming and those of a $2{ }^{\circ} \mathrm{C}$ warming (e.g., Schleussner et al. 2016; Tachiiri et al. 2019b), and their results are summarized in SR1.5 (IPCC 2018).

The Agreement also stipulates that participating countries should reduce their greenhouse gas emissions in accordance with the goals set out in their Nationally Determined Contributions (NDCs). As part of the Agreement, a Global Stocktake (GST) is to be carried out to confirm global progress toward NDCs, and a cross-checking of NDC consistency with the $1.5{ }^{\circ} \mathrm{C}$ and $2.0^{\circ} \mathrm{C}$ targets. The GST will be based on the latest scientific knowledge, and scientific studies that contribute to it are expected to be very valuable.

The demonstration of a fairly linear relationship between cumulative anthropogenic $\mathrm{CO}_{2}$ emission and transient temperature rise is one of the most wellknown results of ESM studies that have contributed to climate change mitigation policies (IPCC 2013). The proportionality constant for this relationship is called the transient climate response to cumulative carbon emissions (TCRE). The allowable future carbon emission level consistent with a given target is termed the remaining carbon budget (IPCC 2018). The value of TCRE is crucial for quantifying the upper limit of the remaining carbon budget consistent with a $2{ }^{\circ} \mathrm{C}$ target, which has often been addressed in international climate negotiations, and a $1.5{ }^{\circ} \mathrm{C}$ target, which was stressed in the Paris Agreement.

To be consistent with the $2{ }^{\circ} \mathrm{C}$ target, the amount of cumulative remaining anthropogenic carbon emissions since the preindustrial era was estimated to be 790-900 $\mathrm{GtC}$ at the time of the publication of AR5 (IPCC 2013). Given that cumulative emission between the preindustrial era and 2013 was approximately 550 PgC (Le Quéré et al. 2018), the remaining carbon budget consistent with the $2{ }^{\circ} \mathrm{C}$ target in 2013 was estimated to be $240-350$ PgC. This roughly corresponds to 25-40 years of anthropogenic carbon emissions at the current (2008-2017 mean) rate of $9.4 \pm 0.5 \mathrm{PgC} / \mathrm{y}$ (Le Quéré et al. 2018). The value is much smaller for the $1.5{ }^{\circ} \mathrm{C}$ target, which gave rise to a pessimistic view that the $1.5{ }^{\circ} \mathrm{C}$ target is unattainable geophysically, even without considering the political difficulties.

This view was shared by some climate scientists well before the publication of SR1.5. In recent years, however, there is accumulating evidence from ESM studies that the remaining carbon budget could be considerably larger than that estimated in AR5 (Goodwin et al. 2018; 
Holden et al. 2018; Millar et al. 2017; Tokarska and Gillett 2018). One of the reasons for this revision is that simulation results published in AR5 had a tendency to overestimate temperature rise per unit carbon emission. These revised results are incorporated into SR1.5, which postulates a higher remaining carbon budget.

Table 1 shows remaining carbon budget estimates in SR1.5 and AR5 converted to values for 2018. There are clearly large uncertainties in the estimates. Temperature data type used in the estimation influences estimated values; global mean surface air temperature (GSAT) uses air temperature near the surface (often at $2 \mathrm{~m}$ height), while global mean surface temperature (GMST) combines 2-m temperature with sea surface temperature from some oceanic regions where observations of $2-m$ temperature are sparse (Richardson et al. 2018). The TCRE used for evaluating the remaining carbon budget also has major uncertainties that are scenario dependent (e.g., Tachiiri et al. 2019a). As part of their review of existing literature, Rogelj et al. (2019) summarized the sources of uncertainty in remaining carbon budget estimates; these include considerable impacts of non- $\mathrm{CO}_{2}$ greenhouse gases, as well as issues related to the use of different temperature data types and carbon cycle feedbacks.

Arora et al. (2020) reported a TCRE value of $1.78 \pm$ $0.41{ }^{\circ} \mathrm{C} \mathrm{EgC}{ }^{-1}$ for a subset of CMIP6 ESMs, which is $9 \%$ higher than that for CMIP5 $\left(1.63 \pm 0.48{ }^{\circ} \mathrm{C} \mathrm{EgC}{ }^{-1}\right)$. This implies a lower value of remaining carbon budget, although its estimate depends on many other factors as stated above and the mean values are not statistically different given the small sample size of available models. While it is beyond the scope of this review to provide precise estimate of remaining carbon budget, it is possible that its value is again lowered when evaluated based on a full set of CMIP6 ESMs.

Table 1 Estimates of the remaining carbon budgets for early 2018 for different mitigation targets. Units: $\mathrm{GtCO}_{2}$

\begin{tabular}{lll}
\hline Target & AR5 & SR1.5 \\
\hline $1.5^{\circ} \mathrm{C}$ & $110\left({ }^{*} 1\right.$, GSAT-based, lower end $)$ & $420-580\left({ }^{*} 3\right.$, GSAT-based $)$ \\
& & $570-770\left({ }^{*} 4\right.$, GMST-based $)$ \\
$2.0^{\circ} \mathrm{C}$ & $720-830\left({ }^{*} 2\right.$, GSAT-based $)$ & $1320-1690\left({ }^{*} 4\right.$, GMST-based $)$ \\
\hline
\end{tabular}

Lower and upper bounds correspond to $66 \%$ - and $50 \%$-tile values, respectively. $\left.{ }^{*} 1\right)$ This value is based on Chapter 2 of the Special Report on Global Warming of $1.5^{\circ} \mathrm{C}$ (SR1.5) (IPCC 2018), which only provides the 66\%-tile value from the beginning of 2011. This was converted to a value for the beginning of 2018 by using a medium estimate of annual anthropogenic emission of $42 \mathrm{GtCO} 2$, as adopted in SR1.5. (*2). These values are based on the Summary for Policymakers (SPM) of the 5th Assessment Report (AR5) (IPCC 2013). Estimates of the $66 \%$ - and $50 \%$-tile values given for the beginning of 2011 in the SPM were converted to values for the beginning of 2018, as above. (*3) These values are taken from Table 2.2 of SR1.5, in which historical warming is defined by global mean surface air temperature (GSAT). (*4) As for *3, but in this case, historical warming is defined by global mean surface temperature (GMST). See text for the definitions of GSAT and GMST
In addition to remaining carbon budget estimates, ESM studies also provide the society with other useful information, for example for climate impact assessments of land use changes associated with various socioeconomic scenarios, and detailed analysis of annual balances of greenhouse gases. Working toward AR6, research institutes from across the world are evaluating these issues using their cutting-edge ESMs and land use models (Alexander et al. 2018; Meiyappan et al. 2014; Olin et al. 2015; Rolinski et al. 2018; Yokohata et al. 2019a). An attempt is being made to organize the efforts of modeling the effects of land use change on climate (Lawrence et al. 2016).

\subsubsection{Decadal prediction of Earth systems}

It is plausible that scientists may be requested to provide projections of air temperature and greenhouse gas concentrations over periods of $5-10$ years for the GST. If possible, it would be desirable to have annual- to decadal-scale projections in addition to projections on the centennial scale. Studies predicting trends over timescales of annual to decadal periods are gaining in popularity (Boer et al. 2016). Unlike traditional centennial projections, decadal predictions require explicit consideration of the natural variability of initial conditions. Data assimilation has been developed for predictions over relatively short timescales, e.g., for numerical weather prediction. It is being further developed to provide a description of the global environment at a certain time that is as close to reality as possible to be used as input for decadal predictions.

Given the increasing demand for detailed global warming projections over long timescales that involve biogeochemical processes, there is a clear need for more accurate predictions on shorter timescales. Using hindcasting and initial fields obtained from data assimilation, a group in Germany demonstrated 4-7 years of predictability in air-sea $\mathrm{CO}_{2}$ exchange over the northern North Atlantic Ocean (Li et al. 2016). Using a perfect model approach, where simulated fields were treated as if they were observations to examine predictability, another group in France has shown 6 years of predictability in the global carbon cycle (Séférian et al. 2018). In Japan, the JAMSTEC is working on a research project to predict air-sea $\mathrm{CO}_{2}$ flux from the equatorial Pacific region using a data assimilation technique (Watanabe et al. 2020).

Decadal prediction with traditional types of Atmosphere-Ocean GCMs has been rapidly growing. Methodologies to address issues such as removing model drift have been compiled (International CLIVAR Poject Office 2011). This knowledge is needed to develop biogeochemical decadal prediction with ESMs, necessitating interdisciplinary collaboration. 


\subsubsection{Links to socioeconomic models}

Human activities affect climate not only through emissions of greenhouse gases from industry and deforestation but also via other mechanisms such as changing surface albedo through expansion of urban areas and croplands. Impacts of temperature rise on labor productivity can also lead to changes in greenhouse gas emission (Matsumoto 2019), thus forming a feedback loop between climate change and human society. Collins et al. (2015) described a possible feedback loop between climate change and society: changes in agricultural productivity related to global warming may affect the amount of cropland needed to support the population, which further alters surface albedo and the degree of global warming. Such interactions could have considerable impacts on climate change projections, especially at regional scales, and need to be addressed as one of the cross-cutting issues between socioeconomics and climate science (Woodard et al. 2019; Yokohata et al. 2019a). An ESM and an IAM developed for socioeconomic projections could be coupled to conduct consistent and comprehensive studies of such interactions. On the basis of the National Center for Atmospheric Research (NCAR)'s Community Climate System Model (CCSM) (Bitz et al. 2011), Jones et al. (2012) developed such a coupled model and analyzed differences between imposing carbon tax only on industrial emissions and on both industrial and deforestation emissions. They found that temperature rise by 2100 could be reduced considerably by taxing only industrial emissions. These results are rather counterintuitive, and are a result of albedo increases and water vapor decreases from deforestation activities.

A group in Japan (Matsumoto et al. 2016) reported that uncertainties in projections of the Earth system, related to climate sensitivity and the carbon cycle, may lead to considerable uncertainties in future carbon price. Indeed, carbon price is often identified as one of the socioeconomic parameters that is the most sensitive to environmental alteration ( $\mathrm{Su}$ et al. 2018; Yamamoto et al. 2014), although, compared with

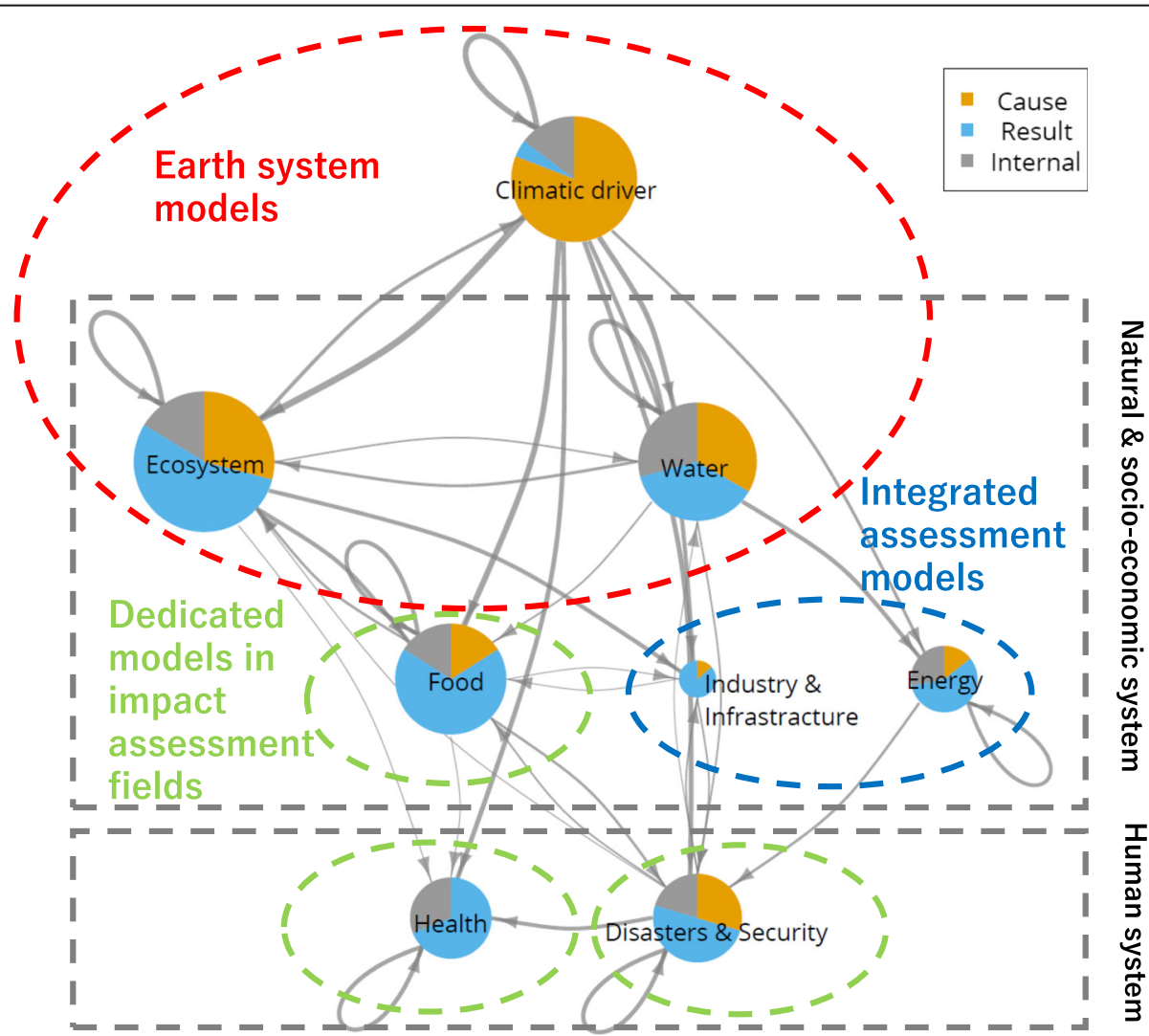

Fig. 4 Climate risks and their cause-effect relationships across different sectors, adapted from Yokohata et al. (2019b). Arrow thickness represents number of risk interconnections. Arrows connecting different sectors indicate intersectoral causal relationships, and those looping back to the same sector represent causal links within each sector. Node size reflects number of risks identified within the sector. Node color indicates the proportion of intersector causes (orange), effects (blue), and intrasector causes and effects (gray). Oval with a red dashed line shows the range covered by Earth system models, as reviewed here. Ovals with blue and green dashed lines show the ranges covered by integrated assessment models and dedicated models in the field of impact assessment, respectively, illustrating the complementarity of the diverse models used in environmental science 
uncertainties associated with other more encompassing socioeconomic projections, those associated with future carbon price are relatively small. This conclusion is largely consistent with the study by Silva Herran et al. (2019), which investigated the effect of climate uncertainties on structural transformations in the global energy system. Although the models used in such studies do not tightly couple socioeconomic and climate models, they indicate a need for hard coupling between models originally developed in totally different fields. On the basis of their survey, Tachiiri et al. (Identifying key processes and sectors in the interaction between climate and socioeconomic systems: a review towards integrating Earth-human systems, submitted) concluded that terrestrial productivity and labor efficiencies are some of the key processes to be included in such coupling. However, parameterization of processes involves large errors. Clearly, such attempts need to proceed with careful consideration of the advantages, disadvantages, and model limitations, as outlined by van Vuuren et al. (2012) and Calvin and Bond-Lamberty (2019).

\section{Conclusions: models as a tool for evolving Earth system science}

This review has briefly described the current status of research applications involving ESMs. Earth system models can be used to study climate change related to anthropogenic greenhouse gas emissions, and also other associated environmental problems, such as ocean acidification through ocean uptake of emitted carbon (Watanabe and Kawamiya 2017; Yamamoto et al. 2012), and impacts of land use change related to biofuel production, cropland expansion, and urbanization (e.g., Smith et al. 2015).

These issues are interconnected and often extend beyond the domain of traditional climate science, necessitating synergetic cooperation among various areas of science and social science, such as agriculture and socioeconomics. Yokohata et al. (2019a, 2019b) developed a scheme to visualize the interlinkages of risks due to climate change, based on an expert review on literature on such individual risks. Figure 4 lumps those risks by sector, such as energy and food, and showing their interand intra-sector impacts. For example, the relationship between the risk of increase in flooding and that of increase in damage to agricultural land is shown by an arrow from "water" to "food" sector, with the former regarded as a cause and the latter an effect. The relationship between change in food distribution leading to destabilization of food supply is represented by an arrow looping within the sector "food."

It can be seen from Fig. 4 that the processes typically dealt with in ESMs have significant impacts on those in other models such as IAMs and impact assessment models, and vice versa, as most notably illustrated by the interaction between food production and ecosystems. A comprehensive approach to global environmental change would require integration of issues traditionally treated in separate disciplines and consideration of their interlinkages.

Furthermore, the search for solutions to global environmental change is a social problem, which requires stakeholder involvement. While scientific problems have been traditionally identified by people with highly specific scientific expertise, identification of scientific problems to be addressed in ESM studies should involve the general public. Ongoing development of ESMs should take an inter- and trans-disciplinary approach, requiring synergetic cooperation through enhanced communications across diverse fields and sectors.

\section{Abbreviations}

AGCM: Atmospheric General Circulation Model; CHASER: Chemical Atmospheric General Circulation Model (AGCM) for Study of Atmospheric Environment and Radiative forcing; CMIP5(6): $5^{\text {th }}\left(6^{\text {th }}\right)$ Phase of the Coupled Model Intercomparison Project; COCO: Centre for Climate System Research (CCSR) Ocean Component Model; CCSM: Community climate system model; CTM: Chemical transport model; ESM: Earth system model; EMIC: ESM with intermediate complexity; GCM: General circulation model; GMST: Global mean surface temperature; GST: Global stocktake; GSAT: Global mean surface air temperature; IPCC: Intergovernmental Panel on Climate Change; JAMSTEC: Japan Agency for Marine-Earth Science and Technology; JMA: Japan Meteorological Agency; MATSIRO: Minimal advanced treatments of surface interaction and runoff; MIROC: Model for Interdisciplinary Research on Climate; NCAR: National Center for Atmospheric Research;

NDC: Nationally Determined Contributions; NPZD: Nutrient, Phytoplankton, Zooplankton, and Detritus; SEIB-DGVM: Spatially Explicit Individual Based Dynamic Global Vegetation Model; Sim-CYCLE: Simulation model of the carbon CYCLE in land ecosystems; SPRINTARS: Spectral Radiation-Transport Model for Aerosol Species; SR1.5: Special Report on Global Warming of $1.5^{\circ} \mathrm{C}$ (IPCC 2018); TCRE: Transient Climate Response to cumulative carbon Emissions; TRIP: Total Runoff Integrating Pathways (Oki and Sud 1998); VISI T: Vegetation Integrative Simulator for Trace Gases; WMO: World Meteorological Organization

\section{Acknowledgements}

This work is supported by TOUGOU, the "Integrated Research Program for Advancing Climate Models" of the Ministry of Education, Culture, Sports, Science and Technology of Japan (Grant Number JPMXD0717935715). Discussion with Junichi Tsutsui of Central Research Institute of Electric Power Industry greatly improved our understanding of the remaining carbon budget and helped us compile Table 1. Authors are grateful to Michio Watanabe and Rumi Ohgaito of the JAMSTEC, who provided useful comments on the manuscript. We thank Dr. Trudi Semeniuk and Dr. Tina Tin from Edanz Group (https://en-author-services.edanzgroup.com/) for editing a draft of this manuscript, and Kazuya Nishina for preparing Fig. 4.

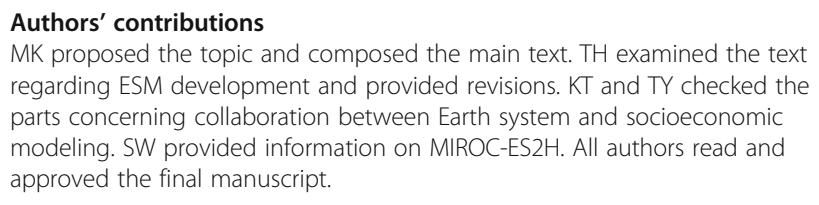
regarding ESM development and provided revisions. $K T$ and TY checked the parts concerning collaboration between Earth system and socioeconomic modeling. SW provided information on MIROC-ES2H. All authors read and approved the final manuscript.

\section{Authors' information}

MK is the director-general of Research Center for Environmental Modeling and Application of the JAMSTEC, which is the section responsible for the development of the MIROC series of models including its Earth system version. 


\section{Funding}

This work is supported by TOUGOU, the "Integrated Research Program for Advancing Climate Models" of the Ministry of Education, Culture, Sports, Science and Technology of Japan (Grant Number JPMXD0717935715).

\section{Availability of data and materials}

Not applicable.

\section{Competing interests}

The authors declare that they have no competing interests.

\section{Author details}

'Japan Agency for Marine-Earth Science and Technology, 3173-25, Showamachi, Kanazawa-ku, Yokohama, Kanagawa 236-0001, Japan. ${ }^{2}$ National Institute for Environmental Studies, 16-2 Onogawa, Tsukuba, Ibaraki 305-8506, Japan.

\section{Received: 24 November 2019 Accepted: 31 August 2020}

Published online: 20 October 2020

\section{References}

Abe M, Takata K, Kawamiya M, Watanabe S (2017) Vegetation masking effect on future warming and snow albedo feedback in a boreal forest region of northern Eurasia according to MIROC-ESM. J Geophys Res 122:9245-9261

Alexander P, Rabin S, Anthoni P, Henry R, Pugh TAM, Rounsevell MDA, Arneth A (2018) Adaptation of global land use and management intensity to changes in climate and atmospheric carbon dioxide. Glob Change Biol 24:2791-2809

Arakawa T, Inoue T, Yashiro H, Satoh M (2020) Coupling library Jcup3: its philosophy and application. Prog Earth Planet Sci 7:6. https://doi.org/10.1186/ s40645-019-0320-z

Arora VK, Boer GJ, Friedlingstein P, Eby M, Jones CD, Christian JR, Bonan G, Bopp L, Brovkin V, Cadule P, Hajima T, llyina T, Lindsay K, Tjiputra JF, Wu T (2013) Carbon-concentration and carbon-climate feedbacks in CMIP5 Earth system models. J Climate 26:5289-5314

Arora VK, Katavouta A, Williams RG, Jones CD, Brovkin V, Friedlingstein P, Schwinger J, Bopp L, Boucher O, Cadule P, Chamberlain MA, Christian JR, Delire C, Fisher RA, Hajima T, Ilyina T, Joetzjer E, Kawamiya M, Koven C, Krasting J, Law RM, Lawrence DM, Lenton A, Lindsay K, Pongratz J, Raddatz T, Séférian R, Tachiiri K, Tjiputra JF, Wiltshire A, Wu T, Ziehn T (2020) Carbonconcentration and carbon-climate feedbacks in CMIP6 models and their comparison to CMIP5 models. Biogeosciences 17:4173-4222. https://doi.org/ $10.5194 / \mathrm{bg}-17-4173-2020$

Bitz CM, Shell KM, Gent PR, Bailey DA, Danabasoglu G, Armour KC, Holland MM, Kiehl JT (2011) Climate sensitivity of the community climate system model, Version 4. J Climate 25:3053-3070

Bodirsky BL, Popp A, Weindl I, Dietrich JP, Rolinski S, Scheiffele L, Schmitz C, Lotze-Campen $\mathrm{H}$ (2012) $\mathrm{N}_{2} \mathrm{O}$ emissions from the global agricultural nitrogen cycle - current state and future scenarios. Biogeosciences 9:4169-4197

Boer GJ, Smith DM, Cassou C, Doblas-Reyes F, Danabasoglu G, Kirtman B, Kushnir Y, Kimoto M, Meehl GA, Msadek R, Mueller WA, Taylor KE, Zwiers F, Rixen M, Ruprich-Robert Y, Eade R (2016) The Decadal Climate Prediction Project (DCPP) contribution to CMIP6. Geosci Model Dev. 9:3751-3777

Bonan GB, Doney SC (2018) Climate, ecosystems, and planetary futures: the challenge to predict life in Earth system models. Science 359:eaam8328. https://doi.org/10.1126/science.aam8328

Boyd PW (2008) Ranking geo-engineering schemes. Nature Geosci 1:722-724

Calvin K, Bond-Lamberty B (2019) Integrated human-earth system modeling — state of the science and future directions. Environ Res Lett 13: 063006

Claussen M, Mysak LA, Weaver AJ, Crucifix M, Fichefet T, Loutre M-F, Weber SL, Alcamo J, Alexeev VA, Berger A, Calov R, Ganopolski A, Goosse H, Lohmann G, Lunkeit F, Mokhov II, Petoukhov V, Stone P, Wang Z (2002) Earth system models of intermediate complexity: closing the gap in the spectrum of climate system models. Climate Dyn 18:579-586

Collins WD, Craig AP, Truesdale JE, Di Vittorio AV, Jones AD, Bond-Lamberty B, Calvin KV, Edmonds JA, Kim SH, Thomson AM, Patel P, Zhou Y, Mao J, Shi X Thornton PE, Chini LP, Hurtt GC (2015) The integrated Earth system model version 1: formulation and functionality. Geoscientific Model Dev 8:22032219
Cox PM, Betts RA, Jones CD, Spall SA, Totterdell IJ (2000) Acceleration of global warming due to carbon-cycle feedbacks in a coupled climate model. Nature 408:184-187

Duce RA, Liss PS, Merrill JT, Atlas EL, Buat-Menard P, Hicks BB, Miller JM, Prospero JM, Arimoto R, Church TM, Ellis W, Galloway JN, Hansen L, Jickells TD, Knap AH, Reinhardt KH, Schneider B, Soudine A, Tokos JJ, Tsunogai S, Wollast R, Zhou M (1991) The atmospheric input of trace species to the world ocean. Glob Biogeochem Cycles 5:193-259

Duce RA, Tindale NW (1991) Atmospheric transport of iron and its deposition in the ocean. Limnol Oceanography 36:1715-1726

Eyring V, Bony S, Meehl GA, Senior CA, Stevens B, Stouffer RJ, Taylor KE (2016) Overview of the Coupled Model Intercomparison Project Phase 6 (CMIP6) experimental design and organization. Geosci Model Dev 9:1937-1958

Friedlingstein P, Bopp L, Ciais P, Dufresne J-L, Fairhead L, LeTreut H, Monfray P, Orr J (2001) Positive feedback between future climate change and the carbon cycle. Geophys Res Lett 28:1543-1546

Friedlingstein P, Cox P, Betts R, Bopp L, von Bloh W, Brovkin V, Cadule P, Doney S, Eby M, Fung I, Bala G, John J, Jones C, Joos F, Kato T, Kawamiya M, Knorr W, Lindsay K, Matthews HD, Raddatz T, Rayner P, Reick C, Roeckner E, Schnitzler KG, Schnur R, Strassmann K, Weaver AJ, Yoshikawa C, Zeng N (2006) Climate-Carbon Cycle Feedback Analysis: Results from the C4MIP Model Intercomparison. J Climate 19:3337-3353

Goodwin P, Katavouta A, Roussenov VM, Foster GL, Rohling EJ, Williams RG (2018) Pathways to $1.5^{\circ} \mathrm{C}$ and $2{ }^{\circ} \mathrm{C}$ warming based on observational and geological constraints. Nature Geosci 11:102-107

Gruber N, Galloway JN (2008) An Earth-system perspective of the global nitrogen cycle. Nature 451:293-296

Hajima T, Kawamiya M, Watanabe M, Kato E, Tachiiri K, Sugiyama M, Watanabe S, Okajima H, Ito A (2014a) Modeling in Earth system science up to and beyond IPCC AR5. Prog Earth Planet Sci 1:29

Hajima T, Tachiiri K, Ito A, Kawamiya M (2014b) Uncertainty of concentrationterrestrial carbon feedback in earth system models. J Climate 27:3425-3445

Hajima T, Watanabe M, Yamamoto A, Tatebe H, Noguchi MA, Abe M, Ohgaito R, Ito A, Yamazaki D, Okajima H, Ito A, Takata K, Ogochi K, Watanabe S, Kawamiya M (2020) Description of the MIROC-ES2L Earth system model and evaluation of its climate-biogeochemical processes and feedbacks. Geoscientific Model Dev. https://doi.org/10.5194/gmd-2019-275

Hasumi H (2000) CCSR Ocean Component Model (COCO) Version 2.1, CCSR Report No. 13. Center for Climate System Research, University of Tokyo, Tokyo, Japan.

Hasumi H, Emori S (2004) K-1 Coupled GCM (MIROC) Description, K-1 technical report. Center for Climate System Research (Univ. of Tokyo), Kashiwa, Japan.

Hibbard KA, Meehl GA, Cox PM, Friedlingstein P (2007) A strategy for climate change stabilization experiments. Eos Transact Am Geophys Union 88:217-221

Holden PB, Edwards NR, Ridgwell A, Wilkinson RD, Fraedrich K, Lunkeit F, Pollitt $H$, Mercure JF, Salas P, Lam A, Knobloch F, Chewpreecha U, Viñuales JE (2018) Climate-carbon cycle uncertainties and the Paris Agreement. Nat Climate Change 8:609-613

Imada Y, Watanabe M, Kawase H, Shiogama H, Arai M (2019) The July 2018 high temperature event in Japan could not have happened without human-induced global warming. SOLA 15A:8-12. https://doi.org/10.2151/ sola.15A-002

Inatomi M, Ito A, Ishijima K, Murayama S (2010) Greenhouse gas budget of a cool-temperate deciduous broad-leaved forest in Japan estimated using a process-based model. Ecosystems 13:472-483

International CLIVAR Project Office (2011) Data and bias correction for decadal climate predictions, CLIVAR Publication Series 150, International CLIVAR Project Office, Qingdao, China.

IPCC (2007) Climate Change 2007: The physical science basis. Contribution of Working Group I to the Fourth Assessment Report of the Intergovernmental Panel on Climate Change. Cambridge University Press, Cambridge and New York

IPCC (2013) The physical science basis. Contribution of Working Group I to the Fifth Assessment Report of the Intergovernmental Panel on Climate Change in: Stocker TF, Qin D, Plattner G-K, Tignor M, Allen SK, Boschung J, Nauels A, Xia Y, Bex V, Midgley PM (Eds.), Cambridge and New York, p. 1535.

IPCC (2017) Chapter outline of the working group I contributions to the IPCC sixth assessment report (AR6).

IPCC (2018) Global warming of $1.5^{\circ} \mathrm{C}$. An IPCC special report on the impacts of global warming of $1.5^{\circ} \mathrm{C}$ above pre-industrial levels and related global 
greenhouse gas emission pathways, in the context of strengthening the global response to the threat of climate change, sustainable development, and efforts to eradicate poverty, in: Masson-Delmotte $V$, Zhai P, Pörtner HO, Roberts D, Skea J, Shukla PR, Pirani A, Moufouma-Okia W, Péan C, Pidcock R, Connors S, Matthews JBR, Chen Y, Zhou X, Gomis MI, Lonnoy E, Maycock T, Tignor M, Waterfield T (Eds.), Cambridge, United Kingdom and New York, NY, USA, p. 616.

IPCC (2019) Decisions adopted by the Panel. 49th Session of the IPCC. https:// www.ipcc.ch/site/assets/uploads/2019/05/IPCC-49_decWoSons_adopted.pdf

Ito A, Myriokefalitakis S, Kanakidou M, Mahowald NM, Scanza RA, Hamilton DS, Baker AR, Jickells T, Sarin M, Bikkina S, Gao Y, Shelley RU, Buck CS, Landing WM, Bowie AR, Perron MMG, Guieu C, Meskhidze N, Johnson MS, Feng Y, Kok JF, Nenes A, Duce RA (2019) Pyrogenic iron: The missing link to high iron solubility in aerosols. Sci Adv 5. https://doi.org/10.1126/sciadv.aau7671

Ito A, Oikawa T (2002) A simulation model of the carbon cycle in land ecosystems (Sim-CYCLE): a description based on dry-matter production theory and plot-scale validation. Ecol Model 151:143-176

Jickells TD, An ZS, Andersen KK, Baker AR, Bergametti G, Brooks N, Cao JJ, Boyd PW, Duce RA, Hunter KA, Kawahata H, Kubilay N, laRoche J, Liss PS, Mahowald N, Prospero JM, Ridgwell AJ, Tegen I, Torres R (2005) Global iron connections between desert dust, ocean biogeochemistry, and climate. Science 308:67-71

JMA (2017) Global Warming Projection Information vol.9, climate change projection for Japan using non-hydrostatic regional climate model under IPCC's RCP8.5 scenario, p 79

Jones AD, Collins WD, Edmonds J, Torn MS, Janetos A, Calvin KV, Thomson A, Chini LP, Mao J, Shi X, Thornton P, Hurtt GC, Wise M (2012) Greenhouse Gas Policy Influences Climate via Direct Effects of Land-Use Change. J Climate 26 3657-3670

Jones C, Robertson E, Arora V, Friedlingstein P, Shevliakova E, Bopp L, Brovkin V, Hajima T, Kato E, Kawamiya M, Liddicoat S, Lindsay K, Reick CH, Roelandt C, Segschneider J, Tjiputra J (2013) Twenty-First-Century Compatible CO2 Emissions and Airborne Fraction Simulated by CMIP5 Earth System Models under Four Representative Concentration Pathways. J Climate 26:4398-4413

Jones CD, Arora V, Friedlingstein P, Bopp L, Brovkin V, Dunne J, Graven H, Hoffman F, llyina T, John JG, Jung M, Kawamiya M, Koven C, Pongratz J, Raddatz T, Randerson JT, Zaehle S (2016) C4MIP_-The Coupled Climate Carbon Cycle Model Intercomparison Project: experimental protocol for CMIP6. Geoscientific Model Dev 9:2853-2880

Kawamiya M, Yoshikawa C, Kato T, Sato H, Sudo K, Watanabe S, Matsuno T (2005) Development of an Integrated Earth System Model on the Earth Simulator. J Earth Simulator 4:18-30

Lawrence DM, Hurtt GC, Arneth A, Brovkin V, Calvin KV, Jones AD, Jones CD, Lawrence P, De Noblet-Ducoudré N, Pongratz J, Seneviratne SI, Shevliakova E (2016) The Land Use Model Intercomparison Project (LUMIP) contribution to CMIP6: rationale and experimental design. Geoscientific Model Dev 9:29732998.

Lawrence DM, Oleson KW, Flanner MG, Thornton PE, Swenson SC, Lawrence PJ, Zeng X, Yang Z-L, Levis S, Sakaguchi K, Bonan GB, Slater AG (2011) Parameterization improvements and functional and structural advances in Version 4 of the Community Land Model. J Adv Model Earth Syst 3. https:// doi.org/10.1029/2011MS00045

Le Quéré C, Andrew RM, Friedlingstein P, Sitch S, Hauck J, Pongratz J, Pickers PA, Korsbakken JI, Peters GP, Canadell JG, Arneth A, Arora VK, Barbero L, Bastos A, Bopp L, Chevallier F, Chini LP, Ciais P, Doney SC, Gkritzalis T, Goll DS, Harris I, Haverd V, Hoffman FM, Hoppema M, Houghton RA, Hurtt G, Ilyina T, Jain AK, Johannessen T et al (2018) Global Carbon Budget 2018. Earth Syst Sci Data 10:2141-2194

Li H, Ilyina T, Müller WA, Sienz F (2016) Decadal predictions of the North Atlantic $\mathrm{CO}_{2}$ uptake. Nature Commun 7:11076. https://doi.org/10.1038/ncomms11076

Martin JH, Fitzwater SE (1988) Iron deficiency limits phytoplankton growth in the north-east Pacific subarctic. Nature 331:341-343

Matsumoto K (2019) Climate change impacts on socioeconomic activities through labor productivity changes considering interactions between socioeconomic and climate systems. J Cleaner Production 216:528-541

Matsumoto K, Tachiiri K, Kawamiya M (2016) Impact of climate model uncertainties on socioeconomics: A case study with a medium mitigation scenario. Comput Oper Res 66:374-383

Meiyappan P, Dalton M, O'Neill BC, Jain AK (2014) Spatial modeling of agricultural land use change at global scale. Ecol Model 291:152-174
Mercure J-F, Pollitt H, Edwards NR, Holden PB, Chewpreecha U, Salas P, Lam A, Knobloch F, Vinuales JE (2018) Environmental impact assessment for climate change policy with the simulation-based integrated assessment model E3ME-FTT-GENIE. Energy Strategy Rev 20:195-208

Millar RJ, Fuglestvedt JS, Friedlingstein P, Rogelj J, Grubb MJ, Matthews HD, Skeie RB, Forster PM, Frame DJ, Allen MR (2017) Emission budgets and pathways consistent with limiting warming to $1.5^{\circ} \mathrm{C}$. Nature Geosci 10:741-747

Moss RH, Edmonds JA, Hibbard KA, Manning MR, Rose SK, van Vuuren DP, Carter TR, Emori S, Kainuma M, Kram T, Meehl GA, Mitchell JFB, Nakicenovic N, Riahi K, Smith SJ, Stouffer RJ, Thomson AM, Weyant JP, Wilbanks TJ (2010) The next generation of scenarios for climate change research and assessment. Nature 463:747-756

Nakajima T, Ohara T, Masui T, Takemura T, Yoshimura K, Goto D, Hanaoka T, Itahashi S, Kurata G, Kurokawa J, Maki T, Masutomi Y, Nakata M, Nitta T, Sudo K, Suzuki K, Tsuruta H, Ueda K, Watanabe S, Xerxes S, Yu Y, Yumimoto K, Zhao S, S-12 Project (2020) A development of reduction scenarios of the short-lived climate pollutants (SLCPS) for mitigating global warming and environmental problems. Progress in Earth and Planetary Science 7:33, https://doi.org/10.1186/s40645-020-00351-1

Ohgaito R, Abe-Ouchi A, O'Ishi R, Takemura T, Ito A, Hajima T, Watanabe S, Kawamiya M (2018) Effect of high dust amount on surface temperature during the Last Glacial Maximum: a modelling study using MIROC-ESM. Climate Past 14:1565-1581

Oki T, Sud YC (1998) Design of total runoff integrating pathways (TRIP) — a global river channel network. Earth Interact 2:1-37. doi.https://doi.org/10.1175/10873562

Olin S, Schurgers G, Lindeskog M, Wårlind D, Smith B, Bodin P, Holmér J, Arneth A (2015) Modelling the response of yields and tissue $C$ : $N$ to changes in atmospheric $\mathrm{CO}_{2}$ and $\mathrm{N}$ management in the main wheat regions of western Europe. Biogeosciences 12:2489-2515

Orr JC, Najjar RG, Aumont O, Bopp L, Bullister JL, Danabasoglu G, Doney SC, Dunne JP, Dutay J-C, Graven H, Griffies SM, John JG, Joos F, Levin I, Lindsay K, Matear RJ, McKinley GA, Mouchet A, Oschlies A, Romanou A, Schlitzer R, Tagliabue A, Tanhua T, Yool A (2017) Biogeochemical protocols and diagnostics for the CMIP6 Ocean Model Intercomparison Project (OMIP). Geosci Model Dev 10:2169-2219. https://doi.org/10.5194/gmd-10-2169-2017

Oschlies A, Garçon V (1999) An eddy-permitting coupled physical-biological model of the North Atlantic: 1. Sensitivity to advection numerics and mixed layer physics. Glob Biogeochem Cycles 13:135-160

Rabalais NN (2002) Nitrogen in Aquatic Ecosystems. Ambio 31:102-112

Richardson M, Cowtan K, Millar RJ (2018) Global temperature definition affects achievement of long-term climate goals. Environ Res J 13:054004. https://doi. org/10.1088/1748-9326/aab305

Rogelj J, Forster PM, Kriegler E, Smith CJ, Séférian R (2019) Estimating and tracking the remaining carbon budget for stringent climate targets. Nature 571:335-342

Rolinski S, Müller C, Heinke J, Weindl I, Biewald A, Bodirsky BL, Bondeau A, BoonsPrins ER, Bouwman AF, Leffelaar PA, te Roller JA, Schaphoff S, Thonicke K (2018) Modeling vegetation and carbon dynamics of managed grasslands at the global scale with LPJmL 3.6. Geosci Model Dev. 11:429-451

Sarmiento JL, Gruber N (2006) Ocean biogeochemical dynamics. Princeton University Press, New York

Sato H, Itoh A, Kohyama T (2007) SEIB-DGVM: a new dynamic global vegetation model using a spatially explicit individual-based approach. Ecol Model 200: 279-307

Schleussner C-F, Lissner TK, Fischer EM, Wohland J, Perrette M, Golly A, Rogelj J, Childers K, Schewe J, Frieler K, Mengel M, Hare W, Schaeffer M (2016) Differential climate impacts for policy-relevant limits to global warming: the case of $1.5^{\circ} \mathrm{C}$ and $2{ }^{\circ} \mathrm{C}$. Earth Syst Dyn 7:327-351

Séférian R, Berthet S, Chevallier M (2018) Assessing the decadal predictability of land and ocean carbon uptake. Geophys Res Lett 45:2455-2466

Silva Herran D, Tachiiri K, Matsumoto K (2019) Global energy system transformations in mitigation scenarios considering climate uncertainties. Appl Energy 243:119-131

Smith P, Davis SJ, Creutzig F, Fuss S, Minx J, Gabrielle B, Kato E, Jackson RB, Cowie A, Kriegler E, van Vuuren DP, Rogelj J, Ciais P, Milne J, Canadell JG, McCollum D, Peters G, Andrew R, Krey V, Shrestha G, Friedlingstein P, Gasser T, Grübler A, Heidug WK, Jonas M, Jones CD, Kraxner F, Littleton E, Lowe J, Moreira JR et al (2015) Biophysical and economic limits to negative CO2 emissions. Nature Climate Change 6:42-50 
Sokolov AP, Schlosser CA, Dutkiewicz S, Paltsev S, Kicklighter DW, Jacoby HD, Prinn RG, Forest CE, Reilly JM, Wang C, Felzer B, Sarofim MC, Scott J, Stone PH, Melillo JM, Cohen J (2005) The MIT Integrated Global System Model (IGSM) Version 2: Model Description and Baseline Evaluation. Joint Program Report Series Report 124:40

Su X, Shiogama H, Tanaka K, Fujimori S, Hasegawa T, Hijioka Y, Takahashi K, Liu J (2018) How do climate-related uncertainties influence 2 and $1.5^{\circ} \mathrm{C}$ pathways? Sustainability Sci 13:291-299

Sudo K, Takahashi M, Kurokawa J, Akimoto H (2002) CHASER: A global chemical model of the troposphere 1. Model description. J Geophys Res 107:ACH 7-1ACH 7-20. https://doi.org/10.1029/2001JD001113

Tachiiri K, Hajima T, Kawamiya M (2019a) Increase of the transient climate response to cumulative carbon emissions with decreasing $\mathrm{CO}_{2}$ concentration scenarios. Environ Res Lett. https://doi.org/10.1088/1748-9326/ab57d3

Tachiiri K, Silva Herran D, Su X, Kawamiya M (2019b) Effect on the Earth system of realizing a $1.5^{\circ} \mathrm{C}$ warming climate target after overshooting to the $2^{\circ} \mathrm{C}$ level. Environ Res Lett: doi:https://doi.org/10.1088/1748-9326/ab5199

Takata K, Emori S, Watanabe T (2003) Development of the minimal advanced treatments of surface interaction and runoff. Glob Planet Change 38:209-222

Takemura T, Okamoto H, Maruyama Y, Numaguti A, Higurashi A, Nakajima T (2000) Global three-dimensional simulation of aerosol optical thickness distribution of various origins. J Geophys Res 105:17853-17873

Tatebe H, Ogura T, Nitta T, Komuro Y, Ogochi K, Takemura T, Sudo K, Sekiguchi M, Abe M, Saito F, Chikira M, Watanabe S, Mori M, Hirota N, Kawatani Y, Mochizuki T, Yoshimura K, Takata K, O'ishi R, Yamazaki D, Suzuki T, Kurogi M, Kataoka T, Watanabe M, Kimoto M (2019) Description and basic evaluation of simulated mean state, internal variability, and climate sensitivity in MIROC6. Geosci Model Dev. 12:2727-2765

Taylor KE, Stouffer RJ, Meehl GA (2011) An overview of CMIP5 and the experiment Design. Bull Am Meteorol Soc 93:485-498

Thompson SL, Govindasamy B, Mirin A, Caldeira K, Delire C, Milovich J, Wickett M, Erickson D (2004) Quantifying the effects of CO2-fertilized vegetation on future global climate and carbon dynamics. Geophys Res Lett 31. https://doi. org/10.1029/2004GL021239

Thornton PE, Lamarque J-F, Rosenbloom NA, Mahowald NM (2007) Influence of carbon-nitrogen cycle coupling on land model response to $\mathrm{CO}_{2}$ fertilization and climate variability. Glob Biogeochem Cycles 21. https://doi.org/10.1029/ 2006GB002868

Tokarska KB, Gillett NP (2018) Cumulative carbon emissions budgets consistent with $1.5^{\circ} \mathrm{C}$ global warming. Nature Climate Change 8:296-299

UNFCCC (2015) Paris Agreement/CP/2015/L.9/Rev.1, in: Secretariat, U. (Ed.).

Van Vuuren DP, Batlle Bayer L, Chuwah C, Ganzeveld L, Hazeleger W, Van Den Hurk B, Van Noije T, O’Neill B, Strengers BJ (2012) A comprehensive view on climate change: coupling of earth system and integrated assessment models. Environ Res Lett 7:024012. https://doi.org/10.1088/1748-9326/7/2/024012

Watanabe M, Kawamiya M (2017) Remote effects of mixed layer development on ocean acidification in the subsurface layers of the North Pacific. J Oceanography 73:771-784

Watanabe M, Suzuki T, O'ishi R, Komuro Y, Watanabe S, Emori S, Takemura T, Chikira M, Ogura T, Sekiguchi M, Takata K, Yamazaki D, Yokohata T, Nozawa T, Hasumi H, Tatebe H, Kimoto M (2010) Improved climate simulation by MIROC5: mean states, variability, and climate sensitivity. J Climate 23:63126335

Watanabe M, Tatebe H, Koyama H, Hajima T, Watanabe M, Kawamiya M (2020) Importance of El Niño reproducibility for reconstructing historical CO2 flux variations in the equatorial Pacific. Ocean Sci Discuss 2020:1-21. https://doi. org/10.5194/os-2020-32

Watanabe S, Hajima T, Sudo K, Nagashima T, Takemura T, Okajima H, Nozawa T, Kawase $H$, Abe M, Yokohata T, Ise T, Sato H, Kato E, Takata K, Emori S, Kawamiya M (2011a) MIROC-ESM 2010: model description and basic results of CMIP5-20c3m experiments. Geoscientific Model Dev 4:845-872

Watanabe S, Sudo K, Nagashima T, Takemura T, Kawase H, Nozawa T (2011 b) Future projections of surface UV-B in a changing climate. J Geophys Res 116. https://doi.org/10.1029/2011JD015749

Watanabe S, Yokohata T (2012) Future Increase in the All-sky UV-B Radiation over Asia Projected by an Earth System Model. J Meteorol Soc Japan 90A:295-305

Wenzel S, Cox PM, Eyring V, Friedlingstein P (2016) Projected land photosynthesis constrained by changes in the seasonal cycle of atmospheric $\mathrm{CO}_{2}$. Nature 538:499-501

Wieder WR, Cleveland CC, Smith WK, Todd-Brown K (2015) Future productivity and carbon storage limited by terrestrial nutrient availability. Nature Geosci 8:441-444
Williamson P, Wallace DWR, Law CS, Boyd PW, Collos Y, Croo P, Denman K, Riebesell U, Takeda S, Vivian C (2012) Ocean fertilization for geoengineering: a review of effectiveness, environmental impacts and emerging governance. Process Saf Environ Prot 90:475-488

WMO (2018) July sees extreme weather with high impacts. https://public.wmo. int/en/media/news/july-sees-extreme-weather-high-impacts, retrieved August $22^{\text {nd }}, 2019$.

Woodard DL, Davis SJ, Randerson JT (2019) Economic carbon cycle feedbacks may offset additional warming from natural feedbacks. Proc Natl Acad Sci USA 116:759-764

Xia JY, McGuire AD, Lawrence D, Burke E, Chen GS, Chen XD, Delire C, Koven C, MacDougall A, Peng SS, Rinke A, Saito K, Zhang WX, Alkama R, Bohn TJ, Ciais P, Decharme B, Gouttevin I, Hajima T, Hayes DJ, Huang K, Ji DY, Krinner G, Lettenmaier DP, Miller PA, Moore JC, Smith B, Sueyoshi T, Shi Z, Yan LM et al (2017) Terrestrial ecosystem model performance in simulating productivity and its vulnerability to climate change in the northern permafrost region. J Geophys Res Biogeosci 122:430-446

Yamamoto A, Abe-Ouchi A, Ohgaito R, Ito A, Oka A (2019) Glacial CO2 decrease and deep-water deoxygenation by iron fertilization from glaciogenic dust. Climate Past 15:981-996

Yamamoto A, Kawamiya M, Ishida A, Yamanaka Y, Watanabe S (2012) Impact of rapid sea-ice reduction in the Arctic Ocean on the rate of ocean acidification. Biogeosciences 9:2365-2375

Yamamoto H, Sugiyama M, Tsutsui J (2014) Role of end-use technologies in longterm $\mathrm{GHG}$ reduction scenarios developed with the BET model. Climatic Change 123:583-596

Yang S, Dong W, Chou J, Feng J, Wei Z, Yan G, Wen X, Wei T, Tian D, Zhu X, Yang $Z$ (2016) Global warming projections using the human-earth system model BNU-HESM1.0. Sci Bull. https://doi.org/10.1007/s11434-016-1176-X

Yokohata T, Kinoshita T, Sakurai G, Pokhrel Y, Ito A, Okada M, Satoh Y, Kato E, Nitta T, Fujimori S, Felfelani F, Masaki Y, lizumi T, Nishimori M, Hanasaki N, Takahashi K, Yamagata Y, Emori S (2019a) MIROC-INTEG-LAND version 1: A global bio-geochemical land surface model with human water management, crop growth, and land-use change. Geosci Model Dev. in press, https://doi. org/10.5194/gmd-2019-184

Yokohata T, Tanaka K, Nishina K, Takahashi K, Emori S, Kiguchi M, Iseri Y, Honda Y, Okada M, Masaki Y, Yamamoto A, Shigemitsu M, Yoshimori M, Sueyoshi T, Iwase K, Hanasaki N, Ito A, Sakurai G, lizumi T, Nishimori M, Lim WH, Miyazaki C, Okamoto A, Kanae S, Oki T (2019b) Visualizing the Interconnections Among Climate Risks. Earth's Future 7:85-100

Yukimoto S, Yoshimura H, Hosaka M, Sakami T, Tsujino H, Hirabara M, Tanak TY, Deushi M, Obata A, Nakano H, Adachi Y, Shindo E, Yabu S, Ose T, Kitoh A (2011) Meteorological Research Institute Earth System Model Version 1 (MRIESM1) —Model Description-, Technical Report of the Meteorological Research Institute, p 83

Zaehle S, Jones CD, Houlton B, Lamarque J-F, Robertson E (2014) Nitrogen availability reduces CMIP5 projections of twenty-first-century land carbon uptake. J Climate 28:2494-2511

\section{Publisher's Note}

Springer Nature remains neutral with regard to jurisdictional claims in published maps and institutional affiliations.

\section{Submit your manuscript to a SpringerOpen ${ }^{\circ}$ journal and benefit from:}

- Convenient online submission

- Rigorous peer review

- Open access: articles freely available online

- High visibility within the field

- Retaining the copyright to your article

Submit your next manuscript at $>$ springeropen.com 